\title{
Plight of the pines
}

\author{
Under attack from pine beetles that are thriving in a warmer climate, Canada's boreal forests \\ could become a sizeable source of emissions in the coming decade. Brian Hoyle reports.
}

\begin{abstract}
$\mathrm{n}$ most temperate regions of
North America, a vivid green expanse of forest patchworked with bright red signals a healthy forest in autumn, but in Canada's British Columbia this visual delight masks an insidious invasion. Under siege by a culprit other than the two-legged human logging variety, lodge-pole pine trees are turning red - and dying - by the dozen.

By the end of 2006, the mountain pine beetle (Dendroctonus ponderosae), so called because of its preference for laying its eggs under the bark of mature lodge-pole pine and jack-pine trees, had ravaged 130,000 square kilometres of forest in western Canada ${ }^{1}$. Though not the first time an outbreak has occurred in the region, the latest is an order of magnitude larger than any previous attack and brings the total area of forest destroyed between 1997 and 2007 to 13 million hectares ${ }^{2,3}$.

Not only is this bad news for the affected trees, whose fate is sealed once the beetle takes hold; the infestation also packs an atmospheric punch. According to scientists who have published a new study in this week's Nature ${ }^{1}$, the assault on British Columbia's pine trees could cause the region to release more carbon dioxide than it absorbs from the atmosphere over the coming decade.

With fewer healthy trees available to absorb the greenhouse gas and more
\end{abstract}

trees decaying and dying, this will further contribute to the warming ${ }^{4}$ that is facilitating the pest's territorial spread ${ }^{5}$.

\section{Predicted emissions from pine beetle damage "are larger than the total average sink of all of Canada's managed forest over the last decade." \\ Werner Kurz}

Led by ecologist Werner Kurz at the Pacific Forestry Centre of the Canadian Forestry Service, the study used a carbon budget model to assess the cumulative impact of various factors - including tree deaths from beetle infestations, forest fires and logging - on the carbon balance of British Columbia's pine forests between 2000 and 2020.

According to the new calculations, by 2020 the beetle outbreak alone will have released 270 megatonnes of carbon dioxide into the atmosphere. That's exactly the amount of greenhouse gas emissions that Canada is committed to reducing by 2012 under the Kyoto Protocol. And given that Canada is far off meeting that target, it may be even harder than once thought for the

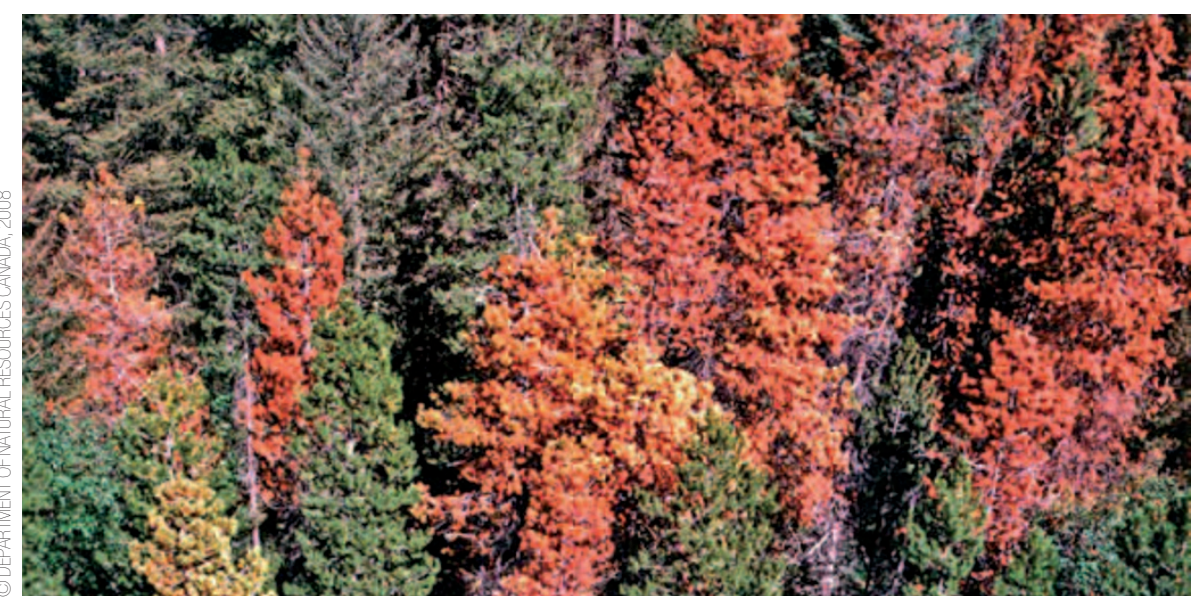

nation to offset its emissions through forest management ${ }^{6}$. Putting it in context, Kurz says, "The predicted emissions are larger than the total average sink of all of Canada's managed forest over the last decade."

\section{WEAKENING SINKS}

In the 15 years before the recent outbreak, says Kurz, the area was, by and large, a carbon sink, with healthy trees absorbing more carbon dioxide than was released by those burned in forest fires, logged for timber or ravaged by pests. But as the pine beetle is strengthening its hold, it is crucial to factor in the effects on the carbon cycle, argue the researchers, especially as the impacts of insects on the global climate are not well understood.

"It's important that we do not ignore processes such as insects," says Kurz. If we did, "we would be leading ourselves into a false sense of security that terrestrial sinks will continue to operate as they have in the past," he explains.

"If indeed Canadian forests will turn to a source of carbon by 2020, this is very serious information," says Corinne Le Quéré, professor of environmental sciences at the University of East Anglia in Norwich, UK, who was not involved in the study.

Yet forests are just one of the Earth's major carbon sinks that are losing strength as the world warms. Recently scientists have also discovered that the Southern Ocean ${ }^{7}$ and North Atlantic ${ }^{8}$ have weakened as carbon sinks in the past two decades, and they fear that this might be typical of the ocean as a whole, which absorbs an estimated 25 per cent of anthropogenic carbon dioxide emissions yearly.

"The impact of one specific region on the total carbon sink may not be all that large but the sum of such impacts could be large," warns Colin Prentice, an Earth-systems scientist from the University of Bristol, UK.

Taken together, the evidence of weakening carbon sinks worldwide makes for ominous projections of how quickly carbon dioxide could accumulate in the atmosphere. Most scientists and policymakers advise that we need to 
stabilize atmospheric greenhouse gas levels at 450 parts per million of 'carbon dioxide equivalent' to have a reasonable chance of avoiding dangerous warming - generally construed as more than $2{ }^{\circ} \mathrm{C}$ above preindustrial temperatures - a task that already looks fraught with difficulties?

\section{OUTLOOK UNCLEAR}

Ultimately, Kurz and colleagues want to see their data, and similar data, being used to improve the estimates from climate models of the potential for forests to sequester emissions.

"Given the state of the art in large-scale modeling, this is simply often ignored because it requires an extra layer of complexity and data," says Kurz.

\section{"If indeed Canadian forests will turn to a source of carbon by 2020 , this is very serious information."}

Corinne Le Quéré

Scott Doney, senior scientist at Woods Hole Oceanographic Institution in Massachusetts, whose research includes studies of ocean and terrestrial carbonclimate feedbacks, agrees. "Part of the art of climate modeling is including processes important to the question being addressed, without adding things simply because you can, or worse, things that you don't understand well."

According to Atul Jain, an atmospheric scientist and modeller at the University of Illinois at Urbana-Champaign, we don't understand such processes well when it comes to the pine beetle. "Climate change is a two-way interaction rather than one-way interaction. Pine beetles could impact climate by the destruction of trees, but at the same time climate change could impact populations of pine beetle," he cautions.

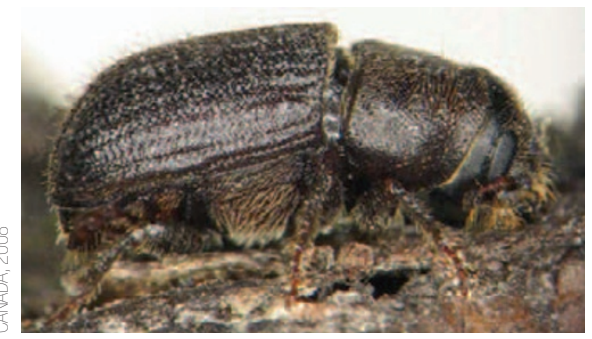

The adult mountain pine beetle (Dendroctonus ponderosae) is less than one centimetre long.

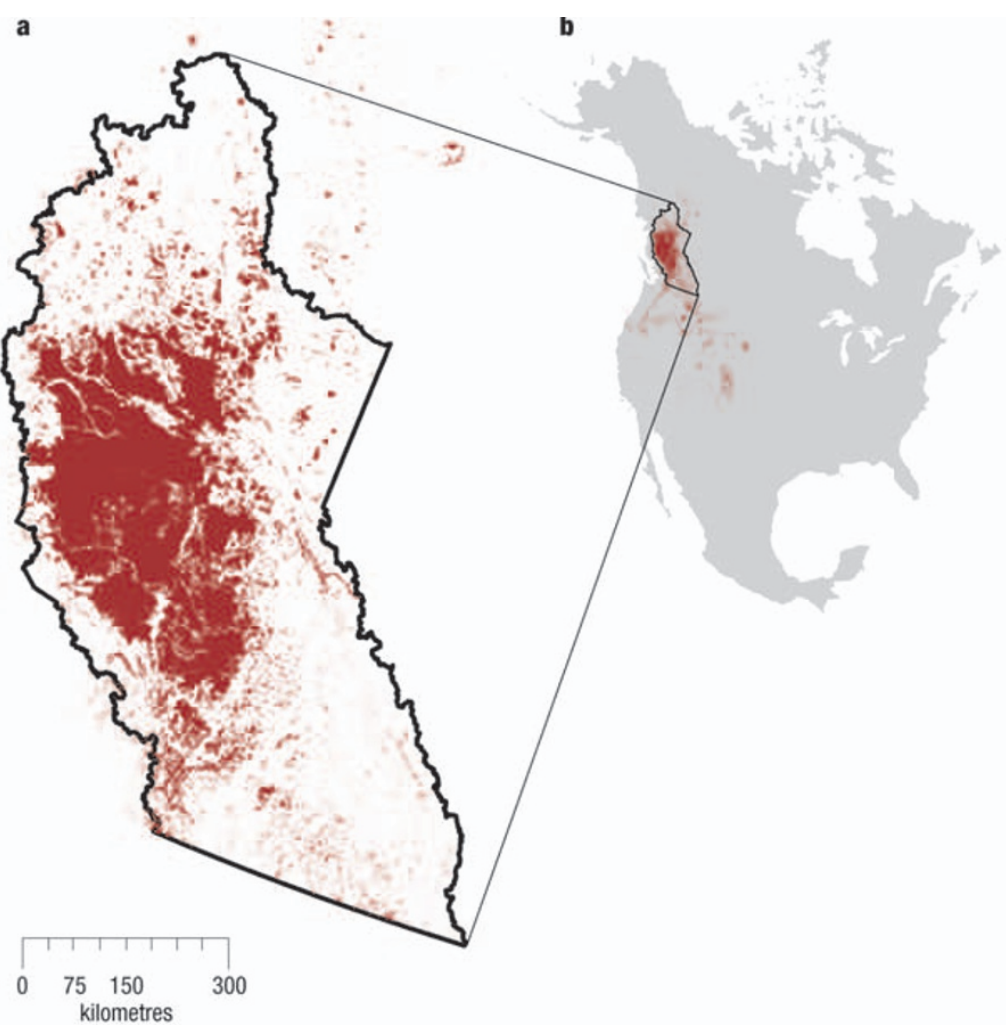

Figure 1 Geographic extent of mountain pine beetle outbreak in North America. a, Extent (dark red) of mountain pine beetle. $\mathbf{b}$, The study area of the new study by Kurz et al. ${ }^{1}$

How long the beetle's environmental punch will last is still somewhat unclear. Although the forest modelled in the new study was beginning to recover by 2020 , the process was not uniform: some areas that had been attacked early showed nearly complete recovery, and other areas attacked recently remained big carbon sources.

And although the scientists expect the forests to bounce back eventually, Wother factors such as forest fires could prevent the region from regaining its status as a carbon sink. "It is possible that climate change could increase the area being burned or increase the impacts of drought on the carbon cycle," says Kurz. That sort of analysis will have to wait for another day.

Modelling aside, how to deal with the real-life problem is an urgent issue. The government's response to the outbreak has been to intensify clear-cut logging of infested stands of trees to slow the spread of the beetle and to quickly send to market any lumber that still holds economic value. But according to Canadian scientist and media personality David Suzuki, "The hyper-pace, scale and intensity of clearcutting threatens to exacerbate greenhouse gas emissions from infested stands."

Furthermore, Suzuki fears that this approach may also lead to more destructive outbreaks by creating even-aged stands of lodge-pole pine, which, as they mature, are preferentially targeted by the beetle. Until the supply of susceptible trees runs out or a cold winter destroys the larvae, there may be little that can be done. If so, and if the new study proves prophetic, even more troubled climatic days may lie ahead.

\section{Published online: 24 April 2008}

\section{doi:10.1038/climate.2008.35}

\section{References}

1. Kurz, W. A. et al. Nature 452, 987-990 (24 April 2008).

2. Mountain Pine Beetle (British Columbia Ministry of Forest and Range, October 2007); http://www.for.gov.bc.ca/hfp/mountain pine_beetle/\#info

3. British Columbia's Mountain Pine Beetle Action Plan 2006-2011 (British Columbia Ministry of Forest and Range, 2006); http:// www.for.gov.bc.ca/hfp/mountain_pine_beetle/actionplan/2006/ Beetle_Action_Plan.pdf

4. Brown S. J., Caesar, J. \& Ferro, C. A. T. J. Geophys. Res. 113, D05115 (2008).

5. Carroll, A. L. et al. Mountain Pine Beetle Initiative Working Paper 2006-14 (Natural Resources Canada, Pacific Forestry Center, 2006); http://mpb.cfs.nrcan.gc.ca/archive/projects/1-02_e.html

6. Kurz, W. A. et al. Proc. Natl Acad. Sci. USA 105, 1551-1555 (2008).

7. Le Quere, C. et al. Science 316, 1735-173 (2007).

8. Schuster, U. \& Watson, A. J. J. Geophys. Res. 112, C11006 (2007).

9. Pielke, R. Jr, Wigley, T. \& Green, C. Nature 452, 531-532 (2008).

Brian Hoyle is a freelance science writer and editor based in Nova Scotia, Canada. 